\title{
Lepromatous Leprosy in the Nose After One Year of Dapsone Treatment: Histopathological Findings
}

\author{
A. C. McDOUGALL \\ and \\ A. G. M. WEDDELL \\ Department of Human Anatomy, Oxford University, \\ Oxford OXI $3 Q X$ \\ and \\ R. J. W. REES* \\ National Institute for Medical Re search, \\ Mill Hill, London NW7 IAA
}

\begin{abstract}
Following one year of supervised dapsone treatment, the histopathology of 32 biopsies of nasal septum and turbinate from 14 lepromatous patients is described. In one patient who may originally have had a borderline element, bacilli had completely disappeared, but they were present in all others, together with cellular changes typical of resolving lepromatous leprosy. In virtually every case, the integrity of overlying respiratory and vestibular epithelium had been restored, thus containing the infiltrate in the submucosa. Although $99 \%$ of all bacilli were fragmented or granular, occasional solid-staining forms were found in macrophages in 4 patients and in 2 of these, solid-staining bacilli were also seen in the cytoplasm of endothelial lining cells of capillaries. A year of dapsone produced marked general improvement in the histopathological appearances, but the finding of solid-staining (and therefore presumably viable) bacilli in several biopsies is clearly disconcerting. Furthermore, some patients were found by a completely independent assessor to have positive noseblows or smears, sometimes associated with epistaxis.

These nasal tissues were compared with skin in each patient, and the study serves as a reminder that the nasal mucous membrane is vascular, delicate, of considerable surface area and "open" to the exterior. Further studies are indicated on the nose in lepromatous leprosy as an important area for bacillary lodgement, multiplication and dissemination and as one in which Myco. leprae might persist despite conventional drug treatment.
\end{abstract}

\section{Introduction}

Following detailed, almost prophetic observations over 75 years ago (Sticker, 1897; Schäffer, 1898), on the importance of the nose in leprosy, this organ did not attract systematic investigation until the publication of Shepard $(1960,1962$,

* Requests for reprints should be addressed to R. J. W. Rees.

Received for publication 22 May, 1975. 
1965) and more recently those of Job et al. (1968) and Pedley (1970, 1973) who re-emphasized the highly bacilliferous nature of the nasal mucosa and nasal mucus. These led to the first comprehensive clinico-histopathological study of the nose, involving 34 patients in India with early untreated lepromatous leprosy, from whom an average of 4 biopsies were taken from particular sites of the septum and turbinates under local anaesthesia; the clinical, bacteriological and histopathological findings in these patients have already been published (Barton, 1974; Davey and Rees, 1974; Davey and Barton, 1973; McDougall et al., 1975). On examination of over 120 biopsies by light microscopy, the histopathology was highly revealing for the tissue localization of Mycobacterium leprae, the high density and morphological index (MI) of bacilli in many situations, and the varied methods of "escape" of bacilli from the tissues into the nasal discharges, and thus to the ex terior.

Immediately after examination, these patients were started on dapsone treatment. In view of the extremely high density and MI of bacilli in most of the pre-treatment tissues, and because of the obvious public health importance of the nasal mucus in lepromatous leprosy, it was considered essential to repeat the nasal biopsies after a period of supervised drug therapy. From the original series, 14 patients satisfying the necessary criteria were available for biopsy on the ENT surgeon's second visit to India, and the present paper describes the histopathology in 32 biopsies taken from their septum and turbinates after one year of dapsone treatment.

\section{Patients and Methods}

From an original group of 34 patients with early, untreated active lepromatous leprosy, 14 who had attended regularly for one year were available for nasal biopsies. These were taken under direct vision, using local anaesthesia, and either dissected out with a small-bladed scalpel or punched. Fixation was in buffered formaldehyde; tissues were embedded in paraffin wax, cut at 4-5 $\mu \mathrm{m}$, and stained with "TRIFF" (Wheeler et al., 1965) and the Fite Faraco modification of Ziehl-Neelsen. From each patient, an average of 2.3 biopsies were taken, 32 in all, made up of 20 turbinate and 12 septal biopsies. The procedure was entirely painless throughout, and there were no complications. From an area of likely activity, a skin biopsy was taken at the same time and processed in exactly the same way.

Dapsone (DDS) was given by mouth, beginning in most cases with small doses, but rising to a standard $300 \mathrm{mg}$ weekly. There was no evidence of toxicity or intolerance and ENL occurred transiently in only one patient during the period of study.

\section{Results}

\section{INTEGRITY OF THE EPITHELIUM}

In every instance, whether from vestibular (squamous epithelium) or respiratory area (pseudo-stratified epithelium) the covering was intact and apparently healthy. All biopsies thus looked "cleaner", more compact and orderly, in marked contrast to many in the original untreated series, where both types of epithelium were often secondarily infected, necrotic, denuded or weakened by direct invasion of inflammatory capillaries accompanied by a highly 
bacillated infiltrate (Fig. 1). In this follow-up series bacilli were not found in prickle cells of squamous epithelium or in the substance of columnar epithelium, nor were they seen escaping in polymorphs or macrophages across the epithelial layer. Even when bacillated and infiltrated-as was frequently the case-the infected submucosa was thus never in open contact with the interior of the nose. The mucous blanket was clean and did not contain bacilli.

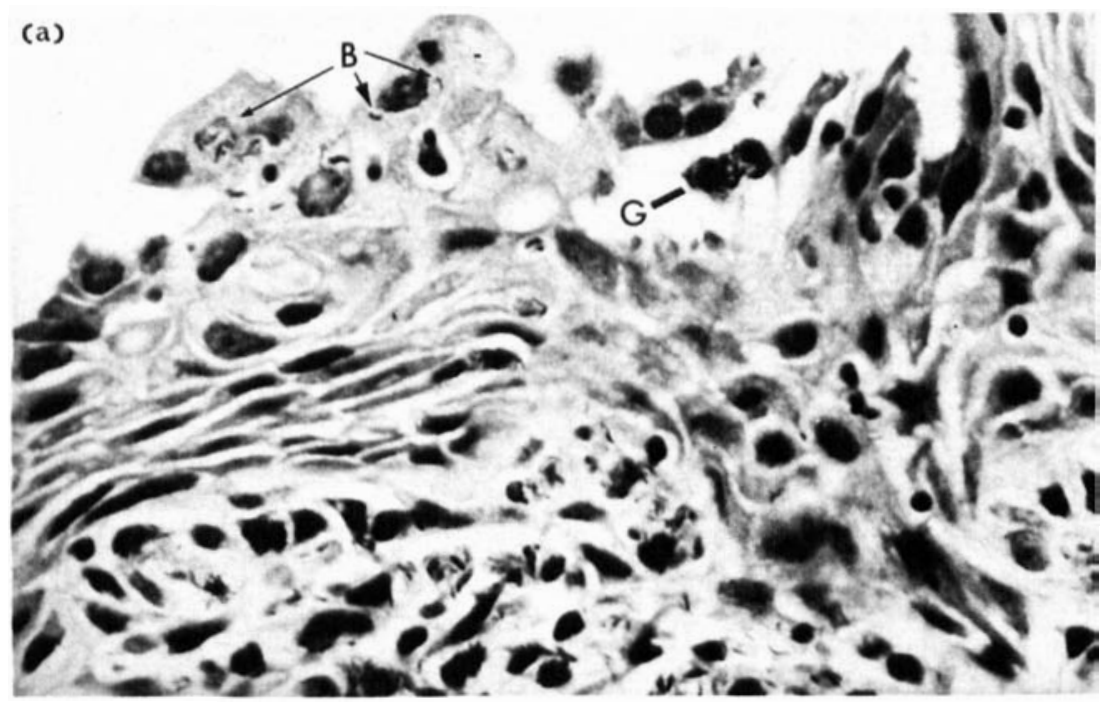

(b)

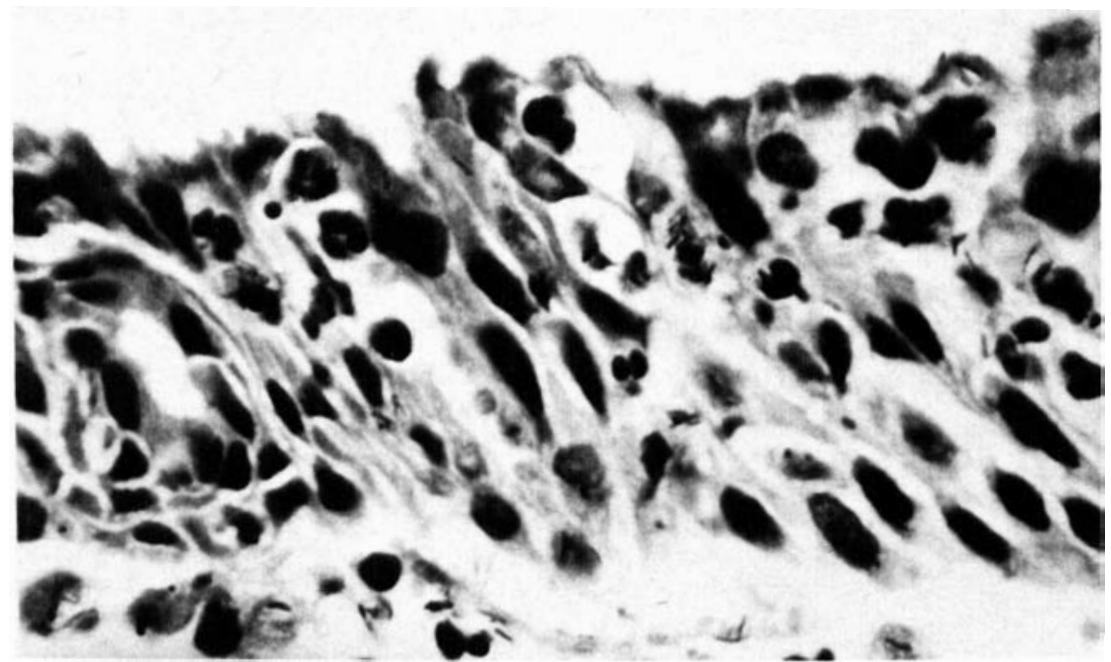

Fig. 1. Pre-treatment biopsies. (a) Squamous epithelium from the vestibular area; a densely bacillated infiltrate rises into the basal layers and solid-staining bacilli (B) and globi (G) are seen escaping from the necrotic epithelial surface into the nasal cavity. (b) Pseudo-stratified columnar epithelium from the respiratory area; solid staining bacilli and globi are seen in macrophages and polymorphs in the substance of the mucous membrane (TRIFF $\times 1250$ ). 


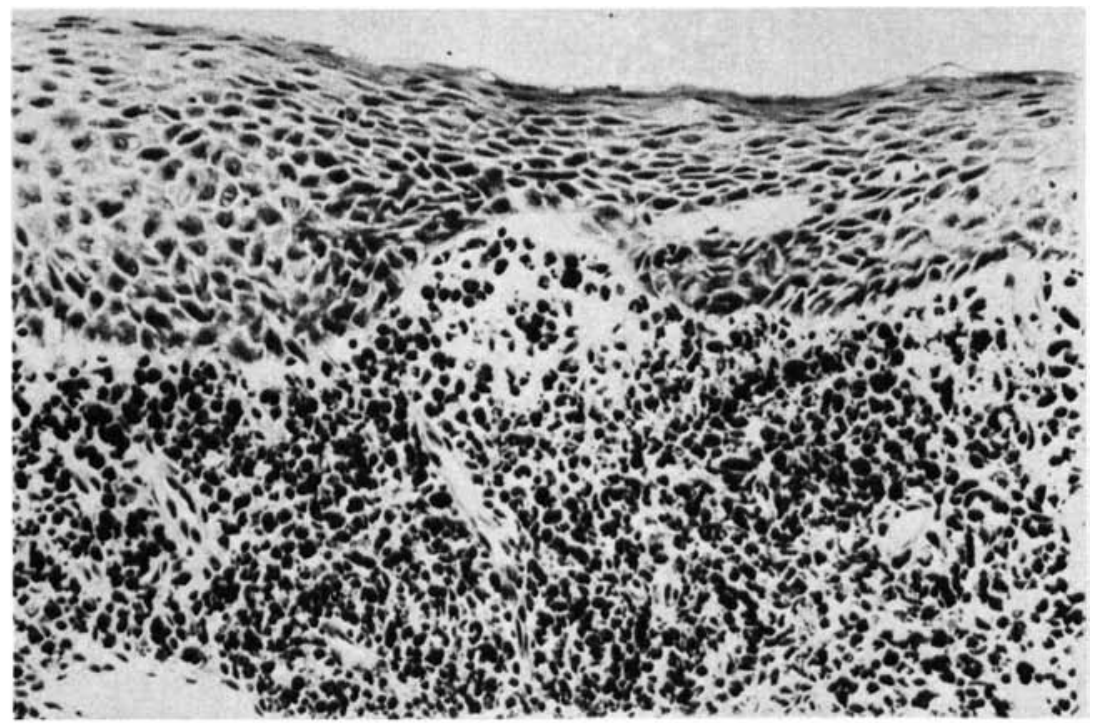

Fig. 2. Pre-treatment biopsy; anterior part of nasal septum. The main constituent of the infiltrate is globi, which rise into direct contact with basal layers of squamous epithelium (Fite-Faraco $\times 312$ ).

\section{SUBEPITHELIAL CLEAR ZONE.}

Whereas the untreated tissues had frequently shown an intensely bacillated infiltrate rising into direct contact with the basal layers of epithelium (Fig. 2), this was not found after one year of dapsone, and in several patients a clear zone was clearly visible in vestibular and respiratory areas (Fig. 3 ).

\section{NUMBERS AND MORPHOLOGY OF BACILLI}

From the 14 patients biopsied, one had no bacilli in any tissue examined, and it is thought this may have been the result of effective therapy in a patient with an original borderline element. In all others, bacilli were present in at least one, and usually in two or three of the tissues submitted; from the total of 32 , only 5 (16\%) were negative on prolonged searching. Using the Bacteriological Index (BI) of Ridley (1964) for the assessment of bacillary density in sections, the BI was zero in $5(16 \%)$, approximately $1-3$ in $7(21.5 \%)$ and $4-5$ in the remaining 20 $(62.5 \%)$. These figures were significantly reduced compared with the original untreated series, but a much greater contrast was obvious in the matter of morphology. Bacilli were universally either fragmented or granular in 26 biopsies (81\%). However, solid-staining bacilli with both Triff and Fite-Faraco techniques, were present in 4 biopsies. These lay mainly in macrophages of the submucosa of septum, inferior or middle turbinates (Fig. 4) but were also seen in 2 cases in the cytoplasm of end thelial lining cells of capillaries (Fig. 6). No bacilli, either solid or non-solid staining were found free in blood of ly mph.

\section{HOST CELLS FOR BACILLI}

In two cases, fragmented or granular bacilli were found in mucous secreting glands and in tiny filaments of the trigeminal nerves in the submucosa. 

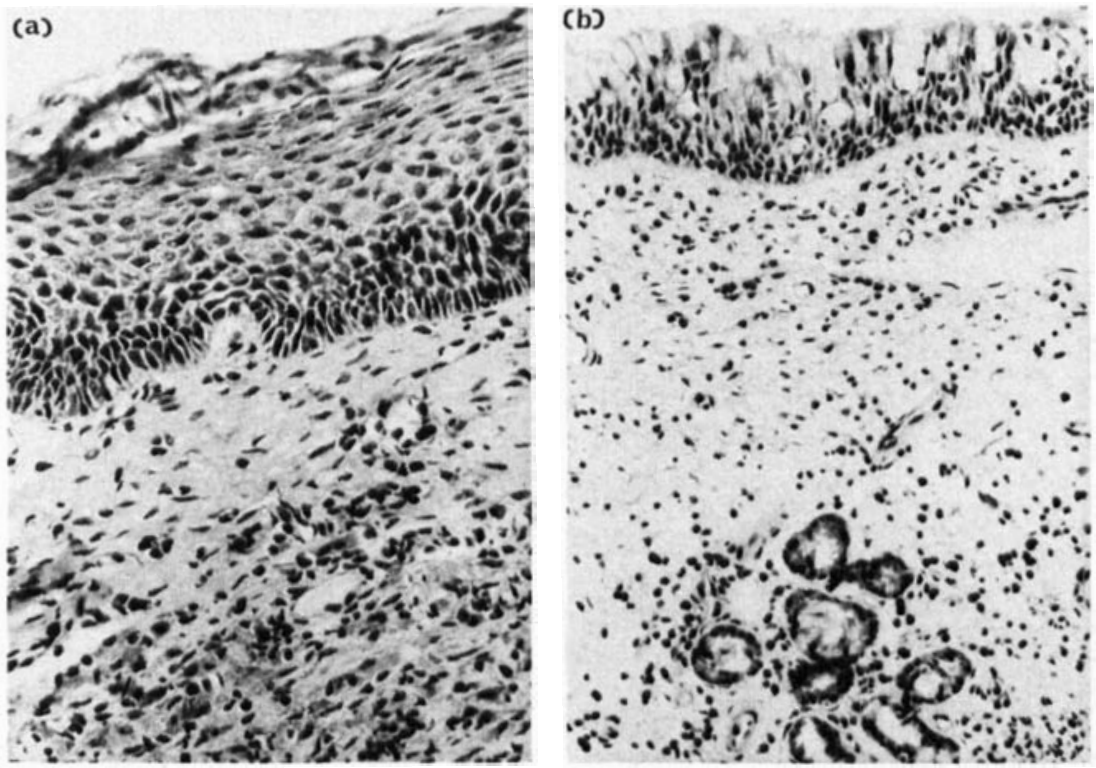

Fig. 3. After a year of dapsone; epithelial integrity has been markedly restored in squamous epithelium of vestibule at (a) and pseudo-stratified columnar at (b) and in both a clear zone is apparent between residual infiltrate and basal epithelium. (a) TRIFF $\times 500$. (b) TRIFF $\times 312$.
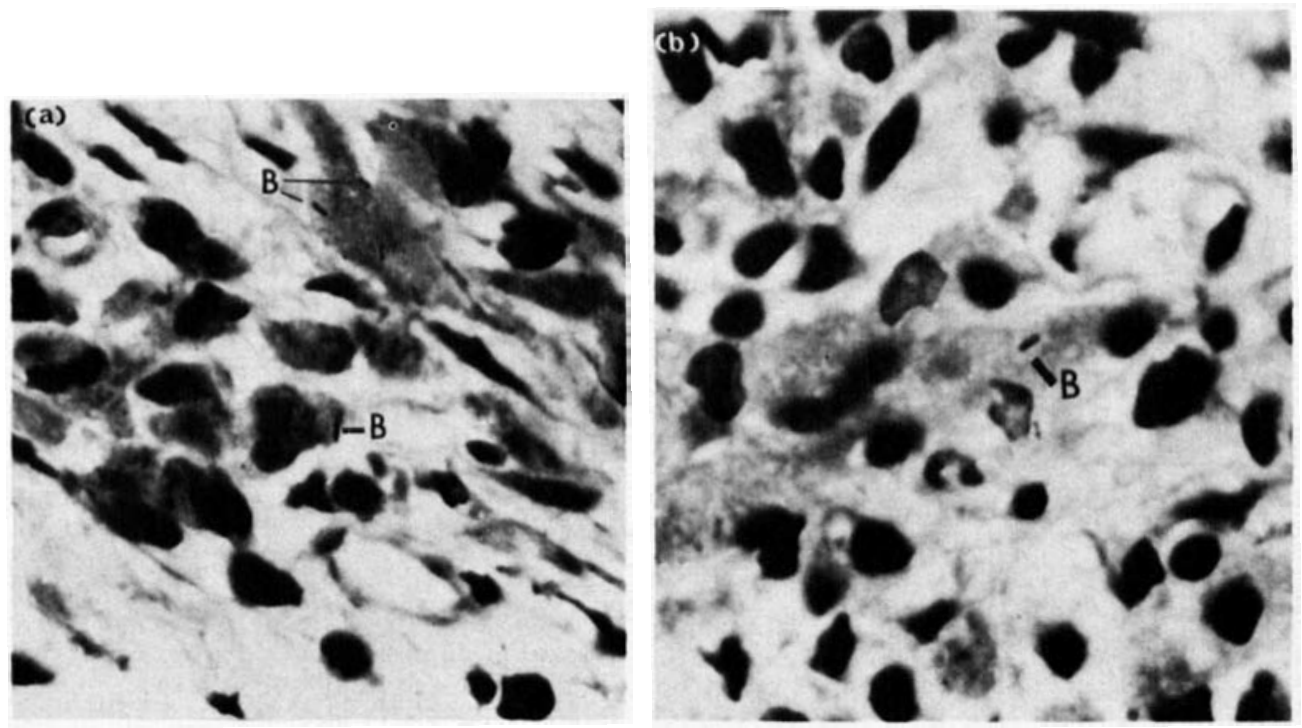

Fig. 4. After a year of dapsone; solid-staining bacilli (B) are seen in the cytoplasm of macrophages in the submucosa of anterior septum (a) and left middle turbinate (b) (TRIFF $\times 1250)$. 

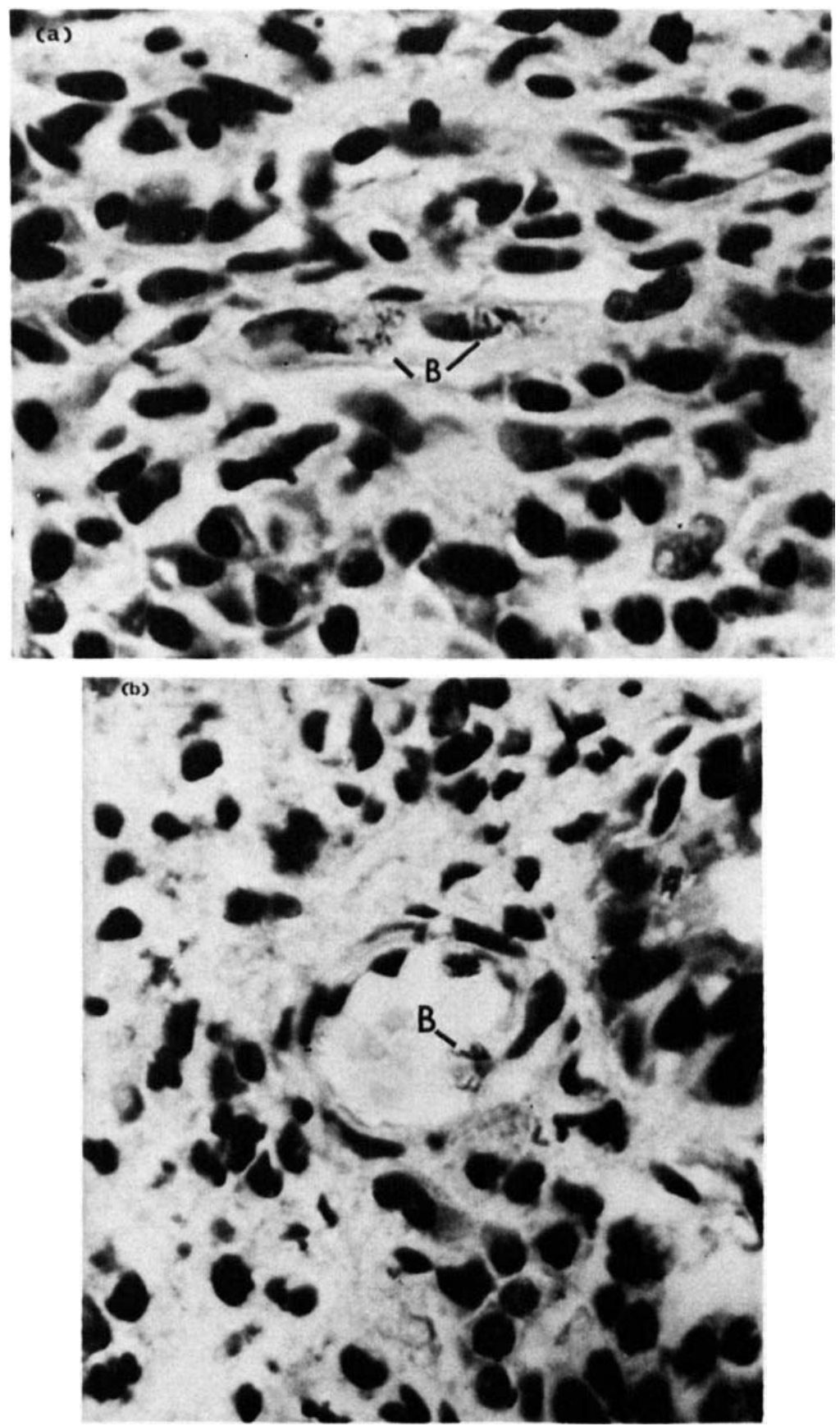

Fig. 5. After a year of dapsone. (a) Left septum, anterior; (b) left middle turbinate. Non-solid staining bacilli are present (B) in the cytoplasm of endothelial lining cells of capillaries in the submucosa (TRIFF $\times 1250$ ). 

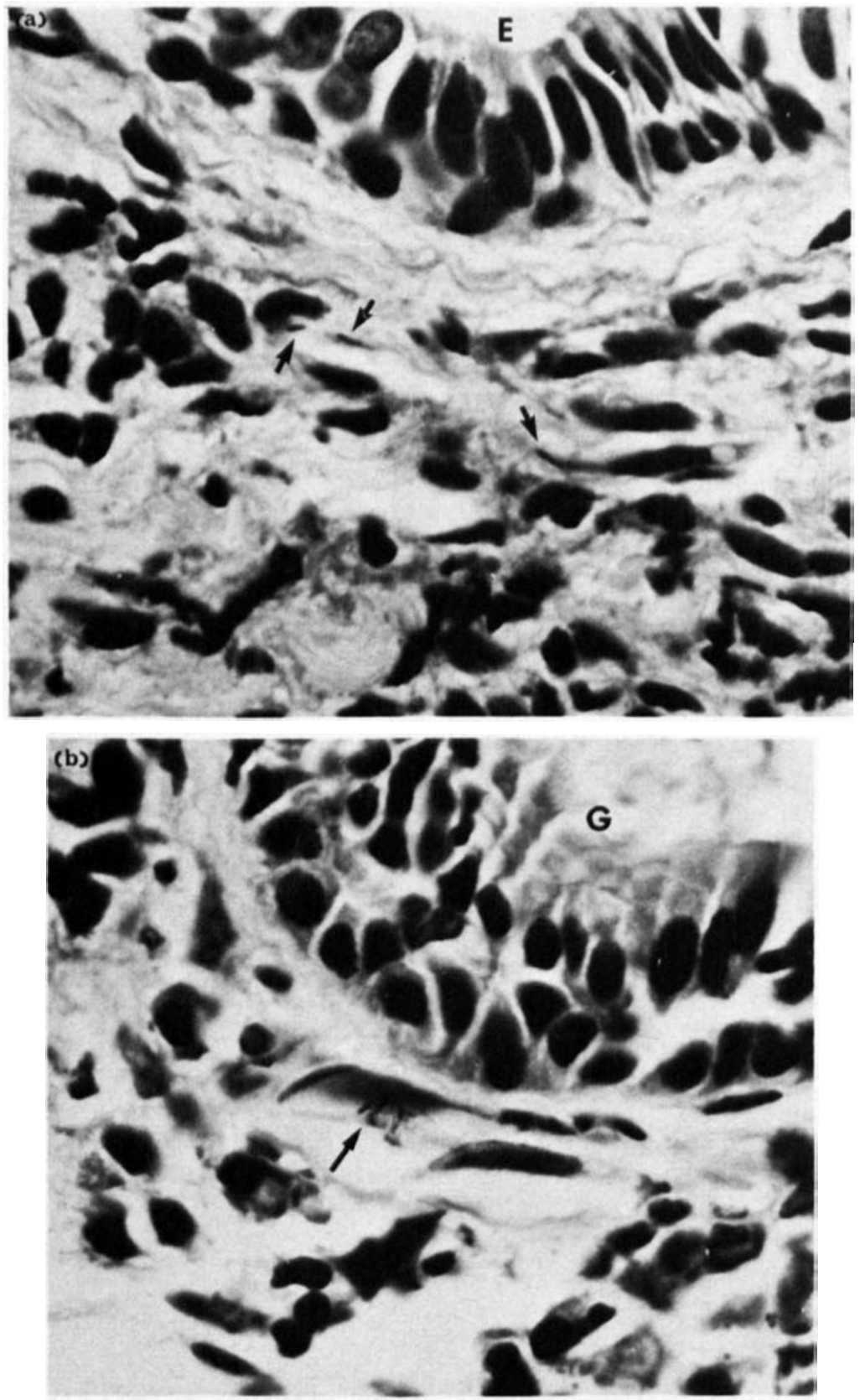

Fig. 6. After a year of dapsone. Solid-staining bacilli (arrowed) are seen in the cytoplasm of capillary endothelial cells; left septum anterior; (a)-above-subjacent to columnar epithelium (E) and (b)-below - adjacent to a mucous secreting gland (G) (Fite-Faraco $\times 1250$ ). 
Polymorphs were not frequent, and in contrast to those of the pre-treatment series, never contained bacilli. Whilst over $90 \%$ of all bacilli were located in the cytoplasm of macrophages, they were not infrequently seen, in fragmented or granular form, in some of the endothelial lining cells of capillaries (Fig. 5), arterioles, venules and venous sinuses.

\section{THE CELLULAR INFILTRATE}

Well over three-quarters of all tissues showed a definite, and often quite widespread infiltrate in the submucosa, immediately apparent at low magnifications. Although this was mainly histiocytic, many fields showed considerable numbers of plasma cells, mast cells, lymphocytes and eosinophils. As noted above, polymorphs were infrequent, compared to the original series, and areas of frank suppuration or necrosis were not found.

\section{HISTOPATHOLOGY OF SKIN BIOPSIES TAKEN AT THE SAME TIME}

All biopsies revealed an infiltrate and bacillary distribution typical of lepromatous leprosy after one year of effective treatment. Foamy vacuolation was frequent in macrophages; bacilli here and elsewhere were all fragmented or granular. Nerves, when shown, were bacillated and often collagenized in both endo- and perineurial areas, with thickening of the latter. Granular bacilli were found in arrector pili muscles in several instances. Particular attention was paid to blood vessel endothelium, and granular bacilli were indeed found in one patient, though in small numbers. The numerous factors which limit any sensible comparison between skin and nasal tissues in lepromatous leprosy will be discussed below, but at this point it may be relevant to add that after one year of treatment, there is a tendency for the nasal pathology, especially under squamous epithelium, to resemble that found in the dermis even to the establishment of a clear sub-epithelial zone.

\section{Discussion}

One year after supervised dapsone treatment, the main points of interest in the histopathology are as follows: (1) a marked reduction in the percentage of solid-staining organisms, (2) the presence of a fairly dense and extensive infiltrate in the submucosa, sometimes pleomorphic but mainly histiocytic and broadly resembling that seen in the dermis of skin, (3) the restoration of intact, "clean" epithelium in both vestibular and respiratory areas, (4) the presence of solid-staining bacilli in endothelial lining cells in 2 patients and of non-solid staining bacilli in the same situation in several others, and (5) of solid-staining bacilli in macrophages in 4 patients.

The importance of the nose in leprosy and of the nasal discharge as a source of infection was emphasized by a group of writers at the end of the last century (Jeanselme and Laurens, 1897; Sticker, 1897; Schäffer, 1898; Goldschmidt, 1891) and later by Muir (1921, 1929) and Rogers and Muir (1946). Important clinical observations were recorded on lesions of the upper respiratory tract and nasal perforation by Pinkerton (1938), Wise (1954) and later by Job, Karat and Karat (1966, 1968) and Goodwin (1967). Reports on the value of nasal smears have almost certainly been confused by the different techniques employed in obtaining them, but in an important series on nasal smears taken in Africa, Browne $(1959,1966 a, b)$ has drawn attention to the fact that they tend to show a 
high $\mathrm{BI}$ and $\mathrm{MI}$, with many globi, and that they may persist in the nose after disappearance from other "routine" sites. In a detailed histopathological study of 120 biopsies from early untreated lepromatous patients (McDougall et al., 1975), the tissue origin of the enormous numbers of bacilli excreted from the nose was clearly revealed. In the present biopsies after one year of treatment there is a very striking reduction in the numbers of bacilli and in their MI, together with a marked improvement in the overlying epithelium. In the pre-treatment tissues, vast accumulations of solid-staining bacilli lay loosely underneath an epithelial area which was necrotic, purulent, denuded (Fig. 1), and thus indeed to be described as an open ulcer (Shepard, 1962). Reports on the rapid disappearance of bacilli from the nose under chemotherapy have been summarized (Goodwin, 1967) and these are in accord with the clinical appearances and most of the nose-blows and smears in this series, and with the recorded reduction of counts of bacilli in nasal washings after treatment (Shepard, 1962). However, the fact that 4 patients still had some solid-staining and thus presumably viable bacilli in sections, and that several in the series had positive nose-blows or smears or epistaxis, underlines the potential hazard of a cavity which is at least $200 \mathrm{~cm}^{2}$ in surface area (Davis and Hertzman, 1957), highly vascular, and probably of special importance for the lodgement and multiplication of Myco. leprae.

Following restoration of epithelial integrity, our material shows that the situation comes to resemble that seen in skin, where the epidermis-despite a relatively rapid turnover time (Cameron and Thrasher, 1971)-normally forms a barrier to the outward movement and escape of bacilli. Apart from radiation injury, the sloughing of a large number of cells from an epithelial surface will usually stimulate the renewal of those which lie below (Evans, 1973, personal communication), but in the case of untreated lepromatous leprosy such large amounts of nasal epithelium and basement membrane may be lost that this mechanism cannot operate. Indeed, the simple structural and histological differences between nasal epithelium and epidermis, particularly as regards strength and blood supply, limit the value of any comparison. It is for instance not generally appreciated that bacilli in skin are to a large extent physically confined, where their morphology represents a mixture of viable and non-viable forms, the latter analogous to the "acid-fast skeletons" which have been described for tuberculosis (Medlar, Bernstein and Steward, 1952). By contrast many tissues from the untreated lepromatous nose have revealed large areas where the MI was very high, but where the bacilli are not physically confined, giving the opportunity for organisms to be continuously discharged from the open, ulcerated mucous surface. This mechanical factor may be of prime importance in accounting for the higher MI found in the nose as compared to skin, although factors such as microvessel architecture (Kanan and Ryan, 1975), temperature, $\mathrm{pH}$, oxygen and carbon dioxide tension may all contribute to the nasal tissues as being particularly favourable for the multiplication of $M y c o$. leprae. Following treatment, the mucosa improves very considerably, but as the histopathology and the accompanying clinical results show, bacilli may still emerge after a year of treatment, no doubt from mucous glands or capillaries and as a result of incidental surface damage from nose-picking or intercurrent infection.

Although the present nasal tissues were much less vascular than those taken before treatment, the comparatively small numbers of bacilli in endothelial lining cells contrast with their profusion, often in solid-staining form, in pre-treatment biopsies. Furthermore, in the latter we have observed bacilli in both solid- and 
non-solid-staining form free in the blood of small nasal vessels, whereas they were not found in this tissue in the present study. Our data do not shed light on the possible method of disposal of such bacilli from nasal vessels, but it would appear likely that a year of dapsone has greatly reduced any contribution which the nose might make to the continuous bacteraemia of lepromatous leprosy (Drutz, Chen and Lu, 1972; Shankara Manja et al., 1972).

It is important to note that our observations are based on biopsies from only 14 patients $(41 \%)$ out of an original series of 34 . Whilst 5 more were known to be taking treatment regularly, this still leaves 15 (44\%) lepromatous patients, who despite all efforts by the hospital staff, were out of control at the time of this follow-up study and not biopsied. It is of course likely that their disease is once again progressive. The fact that bacteriological findings in the present group who did in fact attend for a year of dapsone were not entirely reassuring, emphasizes the need for further study of the nose in lepromatous leprosy as a site of lodgement, multiplication and dissemination of Myco. leprae.

\section{Acknowledgements}

We are indebted to Mr R. P. E. Barton, FRCS, for taking the biopsies, and to Dr L. M. Hogerzeil, Medical Superintendent of the Victoria Hospital, Dichpalli, for permission to refer to patients under his care. This work was supported by grants to A. C. McDougall from the Medical Research Council and the British Leprosy Relief Association (LEPRA).

\section{References}

Barton, R. P. E. (1974). A clinical study of the nose in lepromatous leprosy. Lepr. Rev. 45, 135.

Browne, S. G. (1959). Some observations on the bacteriological index in leprosy. Lepr. Rev. 30, 174.

Browne, S. G. (1966a). Some observations on the morphological index in lepromatous leprosy. Lepr. Rev. 37, 23.

Browne, S. G. (1966b). The value of nasal smears in lepromatous leprosy. Int. J. Lepr. 34, 23.

Cameron, I. L. and Thrasher, J. D. (1971). Cellular and Molecular Renewal in the Mammalian Body. New York and London: Academic Press.

Davey, T. F. and Barton, R. P. E. (1973). Multiple nasal smears in early lepromatous leprosy. Lepr. India 45, 54.

Davey, T. F. and Rees, R. J. W. (1974). The nasal discharge in leprosy; clinical and bacteriological aspects. Lepr. Rev. 45, 121.

Davis, D. L. and Hertzman, A.B. (1957). The analysis of vascular reactions in the nasal mucosa with the photoelectric plethysmograph. Ann. Otol. Rhinol. Lar. 66, 622.

Drutz, D. J., Chen, T. S. N. and Lu, W.-H. (1972). The continuous bacteremia of lepromatous leprosy. New Eng. J. Med., 287, 159.

Goldschmidt, J. (1891). Die Lepra a uf Madeira. Quoted in Dt. med. Wschr. 25, 200.

Goodwin, C. S. (1967). The significance of Mycobacterium leprae in the nasal mucosa, with special reference to Chinese leprosy patients. Lepr. Rev. 38, 181.

Jeanselme, E. and Laurens, J. (1897). Des localisations de la lèpre dans la nez, la gorge et la Larynx. First International Leprosy Congress, Berlin, I, p. 19.

Job, C. K., Karat, A. B. A. and Karat, S. (1966). Histopathological appearance of leprous rhinitis and pathogenesis of septal perforation in leprosy. J. Lar. Otol. 80, 718.

Job, C. K., Karat, A. B. A. and Karat, S. (1968). Pathological study of nasal deformity in lepromatous leprosy. Lepr. India 40, 2.

Kanan, M. W. and Ryan, T. J. (1975). Endonasal localisation of blood borne viable and nonviable particulate matter. Br.J. Derm. 92, 475.

McDougall, A. C., Rees, R. J. W., Weddell A. G. M. and Kanan, M. W. (1975). The histopathology of lepromatous leprosy in the nose. J: Path. 115, 215. 
Medlar, B. M., Bernstein, S. and Steward, S. M. (1952). A bacteriologic study of resected tuberculous lesions. Am. Rev. Tuberc. pulm. Dis. 66, 36.

Muir, E. (1921). Handhook on leprosy. R. J. Grundy. India: Cuttack.

Muir, E. (1929). Leprosy, diagnosis, treatment and prevention. 5th ed. Indian Council of B.E.L.R.A. p. 53.

Pedley, J. C. (1970). Composite skin smears. Lepr. Rev. 41, 31.

Pedley, J. C. (1973). The nasal mucus in leprosy. Lepr. Rev. 44, 33.

Pinkerton, F. J. (1938). Leprosy of the upper respiratory tract. J. Am. med. Ass. 111, 1437.

Ridley, D. S. (1964). Bacterial indices. In Leprosy in Theory and Practice. (Eds R. G. Cochrane and T. F. Davey.) Bristol: John Wright and Sons Ltd. p. 620.

Rogers, L. and Muir, E. (1946). Leprosy (3rd ed.). Baltimore: Williams and Wilkins. p. 32.

Schäffer (1898). Uber der Verbreitung de Leprabacillen von den oberen Luftwegen aus. Arch. Derm. Syph. 44, 159.

Shankara Manja, K., Bedi, B. M. S., Kasturi, G., Kirchheimer, W. F. and Balasubrahmanyan, M. (1972). Demonstration of Mycobacterium leprae and its viability in the peripheral blood of leprosy patients. Lepr. Rev. 43, 181.

Shepard, C. C. (1960). Acid-fast bacilli in nasal excretions in leprosy, and results of inoculation of mice. Am. J. Hyg. 71, 147.

Shepard, C. C. (1962). The nasal excretion of Mycobacterium leprae in leprosy. Int. J. Lepr. 30, 10.

Shepard, C. C. (1965). Temperature optimum of Mycobacterium leprae in mice. J. Bact. 90, 1271.

Sticker, G. (1897). Mittheilungen uber Lepra nach Erfahrungen in Indien un Aegyptien. Dt. med. Wschr. 44, 1063.

Wheeler, E. A., Hamilton, E. G. and Harman, D. J. (1965). An improved technique for the histopathological diagnosis and classification of leprosy. Lepr. Rev. 36, 37.

Wise, H. S. (1954). The genesis of nasal perforation in lepromatous leprosy. Archs Otolar. 59, 306. 